\title{
A Retrospective Evaluation of Pediatric Major Trauma Related to Sport and Recreational Activities in Nova Scotia
}

\author{
Robert S. Green, MD*ઈ; Michael B. Butler, $\mathrm{MSc}^{\dagger}$; Nelofar Kureshi, MBBS, $\mathrm{MHI}^{\ddagger}$; \\ Mete Erdogan, $\mathrm{PhD}, \mathrm{MHI}^{\S}$
}

\section{ABSTRACT}

Objectives: A small proportion of pediatric sport- and recreation-related injuries are serious enough to be considered "major trauma." However, the immediate and long-term consequences in cases of pediatric major trauma are significant and potentially life-threatening. The objective of this study was to describe the incidence and outcomes of pediatric major traumas related to sport and recreational activities in Nova Scotia.

Methods: This study was a retrospective case series. Data on major pediatric traumas related to sport and recreational activities on a provincial scope were extracted from the Nova Scotia Trauma Program Registry between 2000 and 2013. We evaluated frequency, type, severity, and outcomes of major traumas. Outcomes assessed included length of hospital stay, admission to a special care unit (SCU), and mortality.

Results: Overall, 107 children aged three to 18 years sustained a major trauma (mean age 12.5 [SD 3.8]; 84\% male). Most injuries were blunt traumas (97\%). The greatest proportion were from cycling $(59,53 \%)$, followed by hockey $(8,7 \%)$, skateboarding $(7,7 \%)$ and skiing $(7,7 \%)$. The Nova Scotia Pediatric Trauma Team was activated in $27 \%$ of cases. Mean in-hospital length of stay was five days (SD 5.6), and nearly half (49\%) of patients required SCU admission. Severe traumatic brain injury occurred in $52 \%$ of cases, and mortality in five cases.

Conclusions: Over a 13-year period, the highest incidence of pediatric major trauma related to sport and recreational activities was from cycling, followed by hockey. Severe traumatic brain injury occurred in over half of pediatric major trauma patients.

\section{RÉSUMÉ}

Objectif: Les blessures liées au sport et aux activités récréatives chez les enfants sont, dans une faible proportion, suffisamment sérieuses pour être considérées comme des " traumas graves". Toutefois, les conséquences immédiates et lointaines de ces traumas graves chez les enfants sont importantes et potentiellement mortelles. L'étude visait à faire état de la fréquence des traumas graves liés au sport et aux activités récréatives ainsi que des résultats cliniques chez les enfants en Nouvelle-Écosse.

Méthode: L'étude consistait en une série rétrospective de cas. Les données sur les traumas graves liés au sport et aux activités récréatives chez les enfants, à l'échelle provinciale, ont été tirées du Nova Scotia Trauma Program Registry, pour la période de 2000 à 2013. Ont été évalués la fréquence des traumas graves, de même que le type, la gravité et les résultats cliniques. Les résultats évalués comprenaient la durée du séjour à I'hôpital, I'admission dans un service de soins spécialisés (SSS) et la mortalité.

Résultats: Dans I'ensemble, 107 enfants, âgés de 3 à 18 ans, ont subi un trauma grave (âge moyen: 12,5 [écart type $\{\sigma\}: 3,8$ ] ans; garçons: $84 \%$ ). Dans la plupart des cas, il s'agissait de traumatisme contondant (97\%). Les accidents étaient attribuables, en ordre décroissant, au cyclisme (59; $53 \%)$, au hockey $(8 ; 7 \%)$, à la planche à roulettes $(7 ; 7 \%)$ et au ski $(7 ; 7 \%)$. L'équipe Nova Scotia Pediatric Trauma Team a été mobilisée dans $27 \%$ des cas. La durée moyenne du séjour à I'hôpital était de 5 jours $(\sigma: 5,6)$ et presque la moitié $(49 \%)$ des patients ont dû être admis dans un SSS. Des lésions cérébrales traumatiques graves ont été observées dans $52 \%$ des cas et l'accident s'est soldé par la mort dans 5 cas.

Conclusions: Sur une période de 13 ans, c'est le cyclisme qui s'est révélé la principale cause de traumas graves liés au sport et aux activités récréatives chez les enfants, suivi du hockey. Des lésions cérébrales traumatiques importantes ont été observées dans plus de la moitié des traumas graves chez les enfants.

\section{Keywords: pediatrics, injuries, sports}

\section{INTRODUCTION}

The majority of youth sport- and recreation-related injuries are relatively minor and do not require admission to hospital. "Major trauma" in pediatrics is

From the *Department of Emergency Medicine, Dalhousie University, Halifax, NS; +Department of Critical Care Medicine, Dalhousie University, Halifax, NS; ‡Division of Neurosurgery, Dalhousie University, Halifax, NS; and §Trauma Nova Scotia, Halifax, NS.

Correspondence to: Robert S. Green, Room 377 Bethune Building, 1276 South Park Street, Halifax, NS, Canada, B3H 2Y9; E-mail: greenrs@Dal.Ca 
commonly defined using an Injury Severity Score (ISS) threshold between 12 to 15 , and can result from a variety of injury mechanisms, including falls, being struck by another person, and motor vehicle collisions. ${ }^{2,3}$ Although major traumas account for a small proportion of all sport- and recreation-related injuries, serious immediate and long-term consequences are common.

Hockey has been recognized as a high-risk sport in youth. ${ }^{4,5}$ Injuries to the head are particularly concerning due to the risk of traumatic brain injury (TBI) and its potential long-term consequences. In an effort to reduce pediatric sports injuries, Nova Scotia (NS) recently moved to ban body checking at all levels of peewee hockey (ages 11-12). Previous studies using data from the Canadian Hospitals Injury Reporting and Prevention Program (CHIRPP) have reported that hockey, cycling, and soccer are common causes of pediatric sports injuries seen in Canadian emergency departments (EDs) ${ }^{6-9}$ However, the data used for these studies are not representative of "major traumas," since the CHIRPP database does not include patients who die before arrival at the ED or who bypass the ED and are directly admitted to hospital.

There is a lack of information available on the overall patterns of sport- and recreation-related major traumas in youth at the population level. The objective of this study was to use data from a provincial trauma registry to describe the overall patterns of pediatric major traumas related to sport and recreational activities that were seen in NS hospitals between 2000 and 2013. With a pediatric population (ages $0-18$ ) of approximately 200,000 in NS, we hypothesized that hockey was the most common cause of sport- and recreationrelated major trauma.

\section{METHODS}

This retrospective case series study was approved by the Capital Health Research Ethics Board. All patients aged $\leq 18$ years that sustained a sport- or recreation-related major trauma between April 1, 2000, and March 31, 2013, were eligible. The Nova Scotia Trauma Program (NSTP) collects detailed information from multiple sources, including all trauma treatment centres in the province, and records it in the Nova Scotia Trauma Registry (NSTR). ${ }^{10}$ The NSTP definition for "major trauma" is any injury with an ISS $>12$ and an appropriate International Classification of Disease (ICD) External Cause of Injury Code. Penetrating injury cases with an ISS $\geq 9$ are also included in the NSTR, as well as any Trauma Team Activations (TTAs) regardless of ISS. In addition, traumas with an appropriate injury mechanism that resulted in death either at the scene, in the ED, or within 24 hours of admission to a district trauma centre or tertiary trauma centre are included. Excluded are all injuries that do not meet the above criteria, medical errors, and discharges from the ED that were not a TTA.

Using predefined Sport \& Recreation Codes developed by the Canadian Institute of Health Information (CIHI) ${ }^{11}$ we identified all cases of pediatric sport- and recreation-related major trauma from the NSTR during the 13-year study period. Activities involving motorized vehicles (e.g., riding motorcycles, snowmobiles, all-terrain vehicles) are not included in the CIHI Sport \& Recreation Codes, and were not considered for this study. Any duplicate records identified were removed. We collected demographic data, type of injury, use of protective equipment, Glasgow Coma Scale (GCS) score at the scene, ISS, Abbreviated Injury Scale (AIS)-90 Head score, ED assessment, admission to a special care unit (SCU), in-hospital length of stay (LOS), discharge disposition, and discharge status (alive or dead). Data on anatomical diagnosis were collected using ICD-9-CM codes prior to April, 1 2001, and using ICD-10-CA codes after April 1, 2001, when these were implemented by the NSTR. Patients with injuries for which no anatomical lesion was described by an ICD-9-CM or ICD-10-CA code were excluded.

The primary outcome of interest was frequency of pediatric sport- and recreation-related major traumas in NS during the study period. We evaluated secondary outcomes that reflected severity of major trauma, including admission to an SCU (Medical Intensive Care Nursing Unit [ICNU], Surgical ICNU, Trauma ICNU, Pediatric ICNU, Step-down Medical Unit, or Step-down Surgical Unit), overall LOS in-hospital, severe TBI (defined as AIS-90 Head score $\geq 3$ ) and mortality.

The following definitions were used for this study, as defined by the NSTR. Type of injury was defined as blunt, penetrating, or drowning/asphyxia. ED assessment included: a) direct admission-bypassed ED and admitted directly to nursing unit or intensive care unit; b) specialty consult - seen by specialist staff member in ED; or c) Pediatric TTA—seen by pediatric trauma team leader, resident pediatric trauma team leader, and multiple specialties/staff. Discharge disposition 
included discharge to an acute care facility or rehabilitation facility, or discharge home with/without support services. Seasons were defined as autumn (September 21-December 20), winter (December 21-March 20), spring (March 21-June 20), and summer (June 21September 20). We defined sport and recreational activities as any activity identifiable in the NSTR using a CIHI Sport \& Recreation Code. ${ }^{11}$

The sample size for this study was dependent on the number of cases of sport- and recreation-related major trauma seen in NS hospitals and captured in the NSTR during the study period. We used descriptive statistics, including proportions, means, and standard deviations. We calculated age-specific rates of major trauma per 100,000 population using estimates of the pediatric population in NS from Statistics Canada. ${ }^{12}$ In keeping with the NS Department of Health \& Wellness privacy policy, any counts between 1 and 4 are reported as " $\mathrm{n}<5$." All analyses were performed using IBM SPSS Statistics (Version 21) ${ }^{13}$ at a confidence level of $95 \%$.

\section{RESULTS}

During the 13-year study period, there were 1,177 pediatric major traumas in NS, of which 107 (9\%) occurred during a sport or recreational activity (Table 1). The vast majority of injuries were blunt traumas (97\%), and most patients were male (90/107, $84 \%)$. The majority of traumas occurred during the summer season (41/107, 38\%) (Figure 1). In most cases, patients were seen by a specialist staff member in the ED (62/107, 58\%). The NS Pediatric Trauma Team was activated in $27 \%$ of cases (29/107). Of patients with a GCS score recorded at the scene $(58 / 107,54 \%)$, the mean GCS score was 12.1 (SD 4.1). The overall severity of injuries, as measured by mean ISS, was 17.2 (SD 9.1). Over half of pediatric patients (56/107, 52\%) sustained a severe TBI (AIS-90 Head score $\geq 3$ ) and nearly half $(52 / 107,49 \%)$ required admission to an SCU.

Table 2 shows the age-specific rate of major trauma related to sport and recreational activities per 100,000 pediatric population in NS. Males aged 11-14 years had the highest injury rate (11.9), more than eight times greater than the rate for females in the same age group (1.4). The next highest injury rate was in males aged 15-18 years (9.8), which was more than six times greater than the rate for females in the same age group (1.6). Overall, the rate of pediatric major trauma seen in males

\begin{tabular}{|c|c|}
\hline & Major trauma $(\mathrm{N}=107)$ \\
\hline Age-mean (SD) & $12.5(3.8)$ \\
\hline Gender-males, $n(\%)$ & $90(84)$ \\
\hline \multicolumn{2}{|l|}{ Season of injury $-n(\%)$} \\
\hline Summer (21 Jun - Sep 20) & $41(38)$ \\
\hline Spring (21 Mar - 20 Jun) & $34(32)$ \\
\hline Winter (21 Dec - 20 Mar) & $22(21)$ \\
\hline Autumn (21 Sep - 20 Dec) & $10(9)$ \\
\hline \multicolumn{2}{|l|}{ Type of injury - $n(\%)$} \\
\hline Blunt & $104(97)$ \\
\hline Penetrating & $<5$ \\
\hline Drowning/asphyxia & $<5$ \\
\hline Scene GCS - mean (SD) & $12.1(4.1)$ \\
\hline ISS - mean (SD) & $17.2(9.1)$ \\
\hline Severe TBI - $n(\%)$ & $56(52)$ \\
\hline \multicolumn{2}{|l|}{ ED assessment $-n(\%)$} \\
\hline Specialty consult ${ }^{a}$ & $62(58)$ \\
\hline Pediatric Trauma Team ${ }^{\mathrm{b}}$ & $29(27)$ \\
\hline Direct admission ${ }^{c}$ & $12(11)$ \\
\hline Emergency staff ${ }^{\mathrm{d}}$ & $<5$ \\
\hline \multicolumn{2}{|l|}{ Discharge disposition - $n(\%)$} \\
\hline Home $e^{e}$ & $92(86)$ \\
\hline Acute care/Rehab ${ }^{\dagger}$ & $8(8)$ \\
\hline Admission to SCU - $n(\%)$ & $52(49)$ \\
\hline In-hospital LOS - mean days (SD) & $5.0(5.6)$ \\
\hline Mortality $-n(\%)$ & $5(5)$ \\
\hline \multicolumn{2}{|c|}{$\begin{array}{l}\text { GCS = Glasgow Coma Scale; ISS = Injury Severity Score; Severe TBI = severe } \\
\text { traumatic brain injury, defined as having an Abbreviated Injury Scale } 90 \text { Head score } \geq 3 \text {; } \\
\text { SCU = Special care unit (Medical ICNU, Surgical ICNU, Trauma ICNU, Pediatric ICNU, } \\
\text { Step-down medical unit, Step-down surgical unit); LOS = length of stay. } \\
\text { apatient seen by a specialist staff member in ED (includes patients seen by emergency } \\
\text { physicians who are emergency medicine specialists). } \\
\text { bediatric Trauma Team includes pediatric trauma team leader, resident pediatric trauma } \\
\text { team leader, and multiple specialties and staff members activated together if one or } \\
\text { more criteria for Trauma Team Activation are met. } \\
\text { cPatient bypassed ED and admitted directly to nursing unit or intensive care unit. } \\
\text { dPatient seen by ED staff. } \\
\text { ePatient was discharged home with support services in } n<5 \text { cases. } \\
\text { 'Patient discharged to acute care facility or rehabilitation facility. }\end{array}$} \\
\hline
\end{tabular}

(7.8) was more than five times greater than the rate in females (1.5). Major trauma in females only occurred during cycling $(\mathrm{n}=11)$, swimming $(\mathrm{n}<5)$, golf $(\mathrm{n}<5)$, skiing $(\mathrm{n}<5)$, and snowboarding $(\mathrm{n}<5)$.

The severity of pediatric major traumas by type of sport or recreational activity is shown in Table 3. Most major traumas occurred during cycling (59/107, 55\%), followed by hockey $(9 / 107,8 \%)$. The severity of trauma as measured by ISS was greatest in skateboarding (mean ISS 26.0, SD 14.1). The NS Pediatric Trauma Team was activated most often for traumas related to cycling (22/107, $21 \%$ of total; $22 / 59,37 \%$ of cycling). Most of the injuries from cycling were blunt traumas 
(58/59, 98\%). Nearly half $(28 / 59,47 \%)$ of cyclingrelated traumas occurred while in traffic, of which 17 cases $(17 / 59,29 \%)$ involved collision with a vehicle. The remaining cycling-related traumas $(31 / 59,53 \%)$

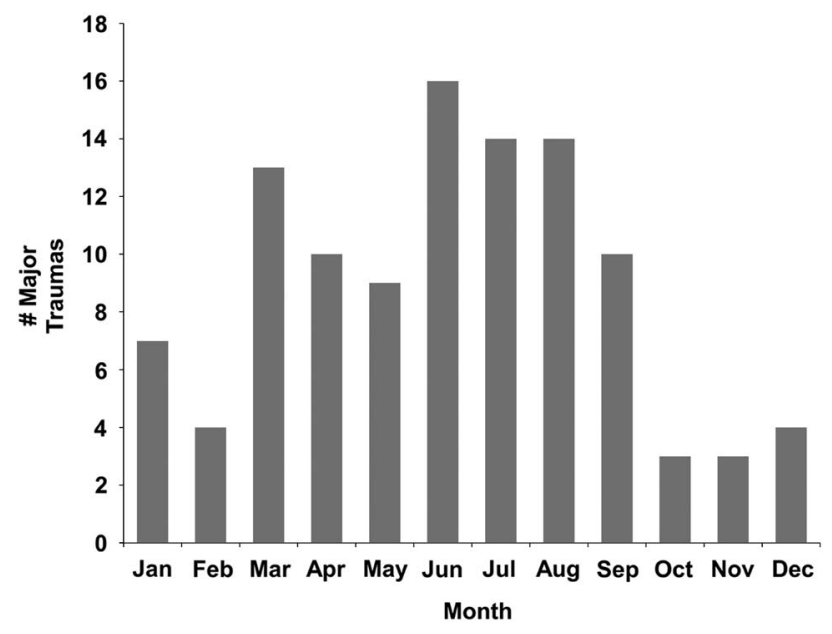

Figure 1. Distribution of pediatric sport and recreationrelated major trauma by month of injury.

\begin{tabular}{|c|c|c|c|}
\hline Age (Years) & Total & Male & Female \\
\hline $3-6$ & 2.5 & 3.6 & 1.3 \\
\hline $7-10$ & 3.4 & 4.7 & 1.9 \\
\hline $11-14$ & 6.7 & 11.9 & 1.4 \\
\hline $15-18$ & 5.8 & 9.8 & 1.6 \\
\hline All Ages (3-18) & 4.7 & 7.8 & 1.5 \\
\hline
\end{tabular}

were non-traffic. Just over one-third (21/59, 36\%) of cyclists were wearing a helmet at time of injury. Figure 2 shows the age of injured cyclists compared with patients injured during all other activities.

Patient outcomes by type of activity are shown in Table 4. Cycling-related trauma accounted for the greatest number of SCU admissions (24/107, 22\% of total; 24/59, $41 \%$ of cycling) followed by hockey (6/107, 6\% of total; $6 / 9,67 \%$ of hockey). The longest in-hospital stays were from injuries related to diving (mean LOS 11.5 days, SD 14.8). The greatest number of severe TBIs were from cycling (32/107, 30\% of total; $32 / 59,54 \%$ of cycling traumas); helmets were not worn at time of injury in $72 \%(23 / 32)$ of cycling-related TBI cases. The five deaths that occurred during the study period resulted from cycling, skateboarding, and swimming.

\section{DISCUSSION}

The results of our study demonstrate that cycling is the most common cause of pediatric sport- and recreationrelated major trauma in NS, followed by hockey. Cycling was responsible for the most cases of severe TBI, while skateboarding was associated with the greatest injury severity as measured by ISS. These findings demonstrate that sport- and recreation-related major trauma, though less frequent than minor trauma in the pediatric population, results in significant morbidity and mortality that has not been thoroughly reported in the literature.

Table 3. Characteristics and severity of major pediatric trauma by type of activity

\begin{tabular}{|c|c|c|c|c|c|c|}
\hline Sport $(N=107)$ & $n(\%)$ & Male $(\%$ of $n)$ & Mean Age (SD) & Mean GCS (SD) & Mean ISS (SD) & Protective Device Worn \% of $n$ \\
\hline Cycling & $59(55)$ & 81 & $11.7(3.6)$ & $12.9(3.5)$ & $16.2(10.1)$ & 36 \\
\hline Hockey & $9(8)$ & 100 & $14.4(2.7)$ & $10(7.1)$ & $18.3(6.9)$ & 100 \\
\hline Skateboarding & $7(7)$ & 100 & $13(4.2)$ & $9.5(5.5)$ & $26.0(14.1)$ & 43 \\
\hline Skiing & $7(7)$ & 86 & $14.9(3.2)$ & $12.3(3.7)$ & $15.6(6.7)$ & 57 \\
\hline Swimming & $5(5)$ & 40 & $11.4(5.9)$ & $8.7(6.7)$ & $19.3(4.9)$ & $\mathrm{n} / \mathrm{a}$ \\
\hline Football & $<5$ & 100 & $10.5(4.9)$ & N/A & $20.5(6.4)$ & 50 \\
\hline Golf & $<5$ & 75 & $9.2(4.0)$ & $\mathrm{N} / \mathrm{A}$ & $16.75(0.9)$ & $\mathrm{n} / \mathrm{a}$ \\
\hline Snowboarding & $<5$ & 75 & $14.7(1.3)$ & $12.3(3.7)$ & $15.6(6.7)$ & 50 \\
\hline Diving & $<5$ & 100 & $15(4.2)$ & $15(0)$ & 8.5 (10.6) & $\mathrm{n} / \mathrm{a}$ \\
\hline Ski-jumping & $<5$ & 100 & 17 (1.4) & $13(0)$ & $16(0)$ & 50 \\
\hline Baseball & $<5$ & 100 & $12.2(3.3)$ & $11.5(2.1)$ & $16.2(0.5)$ & 0 \\
\hline Boxing & $<5$ & 100 & $15(0)$ & N/A & $16(0)$ & 100 \\
\hline Soccer & $<5$ & 100 & $17(0)$ & N/A & $13(0)$ & $\mathrm{n} / \mathrm{a}$ \\
\hline
\end{tabular}




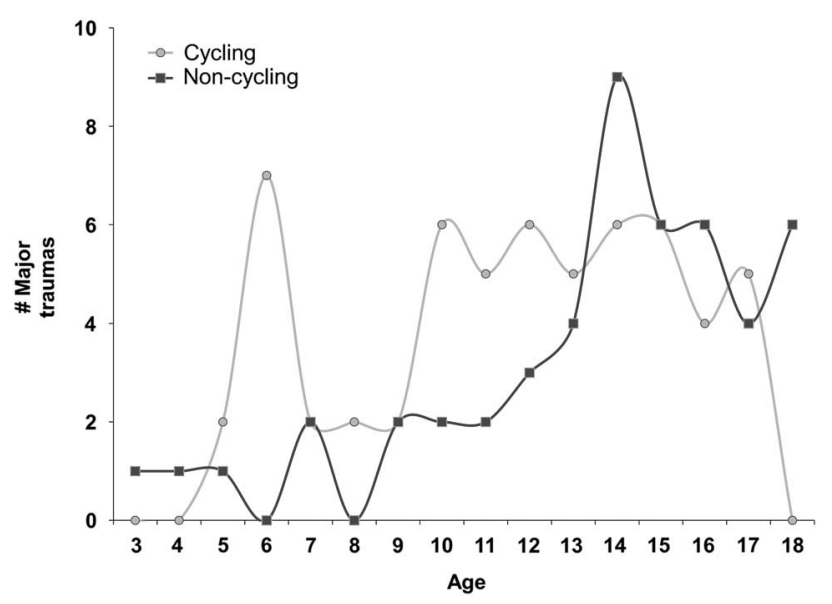

Figure 2. Age of pediatric major trauma patients injured while cycling or during all other activities.

\begin{tabular}{|c|c|c|c|c|}
\hline Sport (N = 107) & $\begin{array}{c}\text { SCU } \\
\text { Admissions } \\
\% \text { of } n\end{array}$ & $\begin{array}{c}\text { Mean days } \\
\text { in-hospital } \\
\text { (SD) }\end{array}$ & $\begin{array}{c}\text { Severe } \\
\text { TBI \% } \\
\text { of } n\end{array}$ & Mortality \\
\hline Cycling ( $n=59)$ & 41 & $4.3(4.3)$ & 54 & $<5$ \\
\hline Hockey $(n=9)$ & 67 & $4.0(2.2)$ & 33 & 0 \\
\hline Skateboarding $(n=7)$ & 43 & $10.7(13.6)$ & 43 & $<5$ \\
\hline Skiing $(n=7)$ & 71 & $7.7(8.1)$ & 43 & 0 \\
\hline Swimming $(n=5)$ & 80 & 4 (1.6) & 40 & $<5$ \\
\hline Football $(n<5)$ & 100 & $7(0)$ & 0 & 0 \\
\hline Golf $(n<5)$ & 25 & $2.7(2.4)$ & 100 & 0 \\
\hline Snowboarding $(n<5)$ & 75 & $4.7(3.6)$ & 50 & 0 \\
\hline Diving $(n<5)$ & 50 & $11.5(14.8)$ & 0 & 0 \\
\hline Ski-jumping $(n<5)$ & 100 & $3(0)$ & 50 & 0 \\
\hline Baseball $(n<5)$ & 25 & $4.2(2.4)$ & 100 & 0 \\
\hline Boxing $(n<5)$ & 0 & $1(0)$ & 100 & 0 \\
\hline Soccer $(n<5)$ & 0 & $1(0)$ & 100 & 0 \\
\hline
\end{tabular}

Comparing the results of the present study with previous sports injury research is problematic due to variability in study designs, populations, and methods by which injuries are defined and measured. While most previous reports of pediatric sport-related major trauma focus on a single sport, ${ }^{14-19}$ our study examined overall patterns of major trauma related to sport and recreational activities using a provincial trauma registry. Similar to previous reports, our study found sportand recreation-related pediatric major trauma to be relatively infrequent in NS, with only 107 cases over a 13-year period ( $9 \%$ of all pediatric major traumas), and most traumas in males aged 11-14 years. A previous report from the United States found serious sport injuries in pediatrics accounted for $13 \%$ of trauma admissions over a 2-year period, with most injuries sustained playing baseball and football. ${ }^{20} \mathrm{~A}$ prior Canadian analysis of severe pediatric trauma in Ontario determined that sports were responsible for $5 \%$ of trauma cases admitted to hospital over a four-year period. ${ }^{21}$ Unlike this prior study from Ontario, we examined injury severity and patient outcomes by type of activity, and we included cycling as a sport/recreational activity, since it has a corresponding CIHI Sport \& Recreation Code in the NSTR. Our results agree with Canadian data from CIHI, showing that cycling injuries are the most common injury from summer sport and recreational activity, with males aged 10-14 years hospitalized most frequently. ${ }^{22}$ Despite evidence that use of bicycle helmets is highly effective at preventing head injury, ${ }^{23}$ our results show that even when helmets are worn $(9 / 32,28 \%)$, the risk of sustaining a severe TBI remains.

The main strength of this study is that data were collected from a dedicated population-based registry that captures all major traumas in NS. However, in some cases information was unknown or incomplete. Furthermore, we are limited by the small size of the population under investigation. Another limitation of this study is that participation data for each activity were unavailable; hence we could not calculate rates of sport- and recreationrelated major trauma. It is possible that participation in more popular sports, like hockey, may be one or two orders of magnitude greater than in sports such as golf or diving, and thus the absolute rates of major trauma presented here would suggest hockey is less dangerous than other activities with lower participation rates.

The results of this study are generalizable in the sense that the data were collected from a populationbased trauma registry based on standardized ICD and CIHI coding, with major trauma and TTA defined a priori. However, variability exists by location with respect to the rules and regulations governing sport and recreational activities, rates of participation, environmental factors, health systems, and the timeliness with which major injuries are recognized and treated. While awareness is increasing among physicians and the public regarding the importance of protective devices, our study demonstrates that even with use $(100 \%$ helmet use in hockey-related trauma, $36 \%$ in cycling-related trauma), it is still possible to sustain major traumatic 
injury, including severe TBI. Further investigation and refinement of public policy is warranted to improve pediatric safety in sport and recreational activities.

\section{CONCLUSION}

Pediatric major trauma related to sport and recreational activity is relatively infrequent in Nova Scotia, with 107 cases recorded over a 13 -year period, accounting for $9 \%$ of all pediatric major traumas during this time. Most major traumas resulted from cycling, followed by hockey. Severe TBI occurred in over half of all pediatric major trauma patients, including a third of hockey-related major traumas, despite $100 \%$ reported helmet use.

Acknowledgements: We thank NSTR Coordinator Beth Sealy for assisting with this project. We also thank Julie Walsh, Charmaine Cooke, and Jill Casey of the NS Department of Health \& Wellness for reviewing this manuscript.

Competing Interests: This study was funded by a Clinician Scientist Award from the Faculty of Medicine, Dalhousie University, Halifax, NS.

\section{REFERENCES}

1. Nalliah RP, Anderson IM, Lee MK, et al. Epidemiology of hospital-based emergency department visits due to sports injuries. Pediatr Emerg Care 2014;30(8):511-5.

2. Baker SP, O'Neill B, Haddon W Jr, et al. The injury severity score: a method for describing patients with multiple injuries and evaluating emergency care. 7 Trauma 1974;14(3):187-96.

3. Champion HR, Copes WS, Sacco WJ, et al. The Major Trauma Outcome Study: establishing national norms for trauma care. 7 Trauma 1990;30(11):1356-65.

4. Shindle MK, Marx RG, Kelly BT, et al. Hockey injuries: a pediatric sport update. Curr Opin Pediatr 2010;22(1):54-60, doi: 10.1097/MOP.0b013e3283350f32.

5. Kennedy J, Green RS, Henteleff H. Penetrating chest trauma secondary to a composite hockey stick. CFEM 2006; $8(6): 437-40$.

6. Fridman L, Fraser-Thomas JL, McFaull SR, et al. Epidemiology of sports-related injuries in children and youth presenting to Canadian emergency departments from 2007-2010. BMC Sports Sci Med Rehabil 2013;5(1):30, doi: 10.1186/2052-1847-5-30.

7. Pakzad-Vaezi K, Singhal A. Trends in paediatric sport- and recreation-related injuries: An injury surveillance study at the British Columbia Children's Hospital (Vancouver, British Columbia) from 1992 to 2005. Paediatr Child Health 2011;16(4):217-21.

8. Cusimano MD, Cho N, Amin K, et al. Mechanisms of teamsport-related brain injuries in children 5 to 19 years old: Opportunities for prevention. PLoS One 2013;8(3):e58868.
9. Babul S, Nolan S, Nolan M, et al. An analysis of sport-related injuries: British Columbia children's hospital emergency department 1999-2003. Int 7 Inj Contr Saf Promot 2007;14(3):192-5.

10. Nova Scotia Trauma Program. 2014, Trauma registry report on injury in Nova Scotia. Halifax: Nova Scotia Trauma Program; 2014. Available at: http://www. cdha.nshealth.ca/system/files/sites/139/documents/traumaregistry-report-injury-nova-scotia.pdf (accessed 10 December 2014).

11. Canadian Institute for Health Information. Ontario trauma registry comprehensive data set data dictionary, May 2014. Ottawa: Canadian Institute for Health Information; 2014. Available at: http://www.cihi.ca/CIHI-ext-portal/pdf/ internet/SERVICES_OTR_CDS_DICT_EN (accessed 8 December 2014).

12. Statistics Canada. CANSIM Table 051-0001: Estimates of population, by age group and sex for Fuly 1, Canada, provinces and territories, annual. Ottawa: Statistics Canada; 1971 [modified September 26, 2014]. Available at: http://www5. statcan.gc.ca/cansim/a26?lang=eng\&retrLang $=$ eng\&id $=05$ $10001 \& p a S e r=\& p a t t e r n=\& s t B y V a l=1 \& p 1=1 \& p 2=-1 \& \mathrm{tab}$ Mode $=$ data Table $\& \operatorname{csid}=($ accessed 22 January 2015$)$.

13. IBM Corp. IBM SPSS Statistics for Windows, Version 21.0. Armonk, NY: IBM Corp; 2012.

14. Polites SF, Sebastian AS, Habermann EB, et al. Youth ice hockey injuries over 16 years at a pediatric trauma center. Pediatrics 2014;133(6):e1601-7, doi: 10.1542/peds. 2013-3628.

15. Vitale MA, Mertz KJ, Gaines B, et al. Morbidity associated with golf-related injuries among children: findings from a pediatric trauma center. Pediatr Emerg Care 2011;27(1):11-2.

16. Pudpud AA, Linares MY. In-line skating: a deadly pediatric activity? Pediatr Emerg Care 1997;13(6):376-9.

17. Shorter NA, Mooney DP, Harmon BJ. Snowboarding injuries in children and adolescents. Am 7 Emerg Med 1999;17(3):261-3.

18. Hayes JR, Groner JI. The increasing incidence of snowboardrelated trauma. 7 Pediatr Surg 2008;43(5):928-30.

19. Walters BS, Wolf M, Hanson C, et al. Soccer injuries in children requiring trauma center admission. 7 Emerg Med 2014;46(5):650-4.

20. Davis JM, Kuppermann N, Fleisher G. Serious sports injuries requiring hospitalization seen in a pediatric emergency department. Am $\mathcal{Z}$ Dis Child 1993;147(9):1001-4.

21. Osmond MH, Brennan-Barnes M, Shephard AL. A 4-year review of severe pediatric trauma in eastern Ontario: a descriptive analysis. 7 Trauma 2002;52(1):8-12.

22. Canadian Institute for Health Information. Cycling Injury Hospitalizations in Canada, 2009-2010. Ottawa: Canadian Institute for Health Information; 2011. Available at: http:// www.cihi.ca/CIHI-ext-portal/pdf/internet/INFO_CY CLING_INJURY_09-10_EN (accessed March 10, 2015).

23. Cripton PA, Dressler DM, Stuart CA, et al. Bicycle helmets are highly effective at preventing head injury during head impact: head-form accelerations and injury criteria for helmeted and unhelmeted impacts. Accid Anal Prev 2014;70:1-7. 